\title{
Tinjauan Literatur: Faktor-Faktor Penyebab Ketidaklengkapan Pengisian Rekam Medis Rawat Inap Rumah Sakit
}

\section{Literature Review : Factors Causing incompleteness Filling Medical Records In Hospital}

\author{
Putu Adiz Siwayana ${ }^{1}$ \\ Ika Setya Purwanti² \\ Putu Ayu Sri Murcittowati ${ }^{3}$ \\ 1,2,3) Jurusan Rekam Medis dan Informasi Kesehatan ; STIKes Wira Medika Bali \\ Jl. Kecak No 9A Gatot Subroto Timur, Denpasar, Bali \\ Email : siwaagus32@gmail.com
}

\begin{abstract}
Every health facility, whether it is primary, secondary, tertiary, is required to maintain medical records in order to achieve administrative order. Incomplete (incomplete) medical records will affect the service process provided by health workers and have an impact on the quality of service of a hospital. This study aims to determine the factors causing the incomplete filling of inpatient medical records. This study uses a literature review method. The strategy in searching literature reviews is using Google Scholar. In the search phase, articles are limited to publications from 2015-2020. The keywords used are the factors causing incomplete medical record filling. The search results obtained 10 articles and then 5 articles were taken. The results of the literature review show that the factors causing the incompleteness of filling in medical records as a whole can be seen from the lack of knowledge, motivation and awareness of medical personnel about medical records. The meeting as a means of communication between caregivers and management has not yet been implemented to discuss evaluation and monitoring as well as sanctions for officers who do not complete medical records. lack of socialization on filling out medical records. Unsystematic arrangement of medical record forms. Limited availability of funds or budget to support medical record service activities. Conclusion Hospitals need to pay attention to the factors causing the incompleteness of filling in medical records so that filling in medical records is complete according to standards. So that the quality of service, especially the quality of patient medical records.
\end{abstract}

Keywords: Factors Causing incompleteness Filling In Hospital Medical Records

\begin{abstract}
Abstrak
Setiap fasilitas kesehatan baik tingkat primer, sekunder, tersier wajib menyelenggarakan rekam medis agar tercapainya tertib administrasi. Ketidaklengkapan (Incomplete) rekam medis akan berpengaruh terhadap proses pelayanan yang diberikan oleh petugas kesehatan dan berdampak pada kualitas pelayanan suatu rumah sakit. Penelitian ini bertujuan untuk mengetahui faktor penyebab ketidaklengkapan pengisian rekam medis rawat inap. Penelitian ini menggunakan metode literatur review. Strategi dalam pencarian literatur review menggunakan Google Scholar. Pada tahap pencarian artikel dibatasi terbitan dari tahun 2015-2020. Kata kunci yang digunakan adalah Faktor Penyebab ketidaklengkapan pengisian rekam medis. Hasil penelusuran artikel didapatkan 10 artikel dan selanjutnya diambil 5 artikel. Hasil dari literatur review didapatkan faktor penyebab ketidaklengkapan pengisian rekam medis secara keseluruhan, penyebabnya dapat dilihat dari kurangnya pengetahuan, motivasi dan kesadaran dari petugas rekam medis tentang rekam medis. Belum terlaksananya rapat sebagai wadah komunikasi antara pemberi asuhan dan manajemen yang membahas evaluasi dan monitoring serta sanksi bagi petugas yang tidak mengisi rekam medis dengan lengkap. kurangnya sosialisasi pengisian rekam medis. Susunan formulir rekam medis yang
\end{abstract}


tidak sistematis. Terbatasnya ketersediaan dana atau anggaran untuk mendukung kegiatan pelayanan rekam medis. Kesimpulan Rumah sakit perlu memperhatikan faktor penyebab ketidaklengkapan pengisian rekam medis sehingga pengisian rekam medis menjadi lengkap sesuai dengan standar. Sehingga mutu dari pelayanan terutama mutu rekam medis pasien.

Kata kunci : Faktor Penyebab ketidaklengkapan pengisian rekam medis rawat inap Rumah sakit

\section{Pendahuluan}

Rekam medis berisikan catatan dan dokumen tentang identitas pasien, seperti pemeriksaan, pengobatan, tindakan dan pelayanan yang telah diberikan kepada pasien. Kualitas rekam medis dapat dilihat pada kelengkapan, kesesuaian, ketepatan isi, serta perlindungan terhadap informasi yang terkandung di dalam rekam medis tersebut. Rekam medis dikatakan lengkap apabila catatan medis tersebut telah berisi seluruh informasi tentang pasien, sesuai dengan formulir yang telah disediakan. Rekam medis berfungsi untuk memelihara dan menyediakan informasi bagi semua pihak yang terlibat dalam memberikan pelayanan kesehatan kepada pasien (Permenkes No. 269 Tahun 2008).

Kelengkapan rekam medis merupakan hal yang sangat penting karena berpengaruh terhadap proses pelayanan yang diberikan oleh petugas kesehatan dan berdampak pada kualitas pelayanan suatu rumah sakit. Salah satu cara menilai mutu pelayanan rumah sakit, dapat dilihat dari aspek pengelolaan rekam medis. Rekam medis adalah milik rumah sakit sedangkan isi dari rekam medis merupakan milik pasien. Kelengkapan pengisian rekam medis 24 jam setelah pelayanan dengan standar $100 \%$ adalah syarat mutlak yang tercantum dalam Standar Pelayanan Minimal Rumah Sakit (Kepmenkes No. 129 Tahun 2008).

Ketidaklengkapan rekam medis menjadi salah satu masalah karena rekam medis seringkali merupakan satu-satunya catatan yang dapat memberikan informasi terperinci tentang apa yang sudah terjadi selama pasien dirawat di rumah sakit. Dokter, perawat, petugas rekam medis, pimpinan rumah sakit dan seluruh staf mempunyai tanggungjawab terhadap rekam medis tetapi penanggungjawab utama akan kelengkapan rekam medis terletak pada dokter yang merawat pasien tersebut (Permenkes No. 269 Tahun 2008).

Ketidaklengkapan pengisian rekam medis membuat terhambatnya hak pasien terhadap dari isi rekam medisnya, mempersulit proses klasifikasi dan kodefikasi penyakit, terhambatnya proses pembuatan laporan rumah sakit, terhambatnya pembuatan tanda bukti untuk kasus kepolisian dan hukum, dan menghambatnya proses pengajuan klaim ansuransi milik pasien. Ketidaklengkapan pengisian rekam medis dapat mempengaruhi mutu pelayanan dan keselamatan pasien (Nurhadiah dkk., 2016).

Ada faktor faktor ketidaklengkapan pengisian rekam medis untuk mencapai target $100 \%$ lengkap dalam 24 jam setelah selesai pelayanan. Menurut (Cicilia et al., 2015) faktor kelengkapan pengisian rekam medis dapat dilihat yaitu 1. Man meliputi pengetahuan dan motivasi dari sumber daya manusia seperti para pemberi asuhan atau Dokter, Perawat, Bidan 2. Machine meliputi aspek kebijakan 3. Method meliputi aspek pelaksanaan 4. Material meliputi aspek alat atau bahan 5. Money meliputi aspek (pendanaan).

Berdasarkan literatur review yang diperoleh Menurut (Devhy, 2019) persentase kelengkapan identifikasi pasien pada rekam medis rawat inap di rumah sakit Ganesha sebanyak 95\% rekam medis. Kelengkapan identitas dokter pada rekam medis rawat inap di rumah sakit ganesa sebanyak $96,8 \%$ rekam medis dan tidak lengkap sebanyak $3,2 \%$ rekam medis. Persentase kelengkapan identitas perawat pada rekam medis rawat inap di rumah sakit ganesa didapatkan sebanyak $85,3 \%$ rekam medis dan tidak lengkap sebanyak $14,7 \%$ rekam medis. 
Persentase kelengkapan rekam medis rawat inap di Rumah Sakit Ganesha di Kota Gianyar didapatkan sebesar 95,8\% rekam medis dan tidak lengkap sebesar 4,2\% rekam medis.

Mengingat pentingnya rekam medis dalam menciptakan informasi yang berkesinambungan, maka penulis tertarik melakukan telaah literatur lebih lanjut mengenai Faktor Penyebab Ketidakelengkapan Pengisian Rekam Medis Rawat Inap Rumah Sakit.

\section{Metode}

Metode yang digunakan dalam literature review ini menggunakan metode review dari hasil penelitian yang dipublikasikan mulai tahun 2015-2020. Kriteria inklusi yaitu semua penelitian yang di review berupa penelitian yang berkaitan dengan Faktor Penyebab ketidaklengkapan pengisian rekam medis kata kunci pencarian adalah Faktor Penyebab ketidaklengkapan pengisian rekam medis

Pencarian literatur dengan penelusuran artikel penelitian yang sudah terpublikasi dengan menggunakan Google Scholar dengan kata kunci Faktor Penyebab ketidaklengkapan pengisian rekam medis. Hasil pencarian diperoleh 10 artikel sesuai dengan kata kunci. Kemudian artikel yang didapatkan di saring berdasarkan full text dan publication date 2015-2020 ditemukan 7 artikel. Dari 7 artikel di review kembali terkait dengan faktor Penyebab ketidaklengkapan pengisian rekam medis, selanjutnya 7 artikel ini discreening berdasarkan kriteria inklusi dan ekslusi dan didapatkan 5 artikel.

\section{Hasil dan Pembahasan}

Kelengkapan pengisian rekam medis 24 jam setelah pelayanan dengan standar $100 \%$ adalah syarat yang tercantum dalam Standar Pelayanan Minimal Rumah Sakit (Kepmenkes No. 129 Tahun 2008). Ketidaklengkapan dokumen rekam medis menjadi salah satu masalah karena rekam medis merupakan alat bukti tertulis tentang proses pelayanan yang diberikan dokter dan tenaga kesehatan lainnya kepada pasien (Hatta, 2013). Ketidaklengkapan pengisian rekam medis menggambarkan pelayanan kesehatan yang diberikan dan mutu pelayanan rekam medis. Ketidaklengkapan pengisian rekam medis mengakibatkan dampak internal dan eksternal karena hasil pengolahan data menjadi dasar pembuatan laporan baik internal rumah sakit maupun bagi pihak eksternal (Depkes, 2006).

Tabel 1. Hasil literatur Review

\begin{tabular}{|c|c|}
\hline Faktor & Hasil \\
\hline Man/manus & $\begin{array}{l}\text { 1. Pengetahuan, motivasi yang } \\
\text { rendah dari petugas medis } \\
\text { 2. Kesadaran dokter untuk } \\
\text { mengisi rekam medis } \\
\text { kurang } \\
\text { 3. Kurangnya SDM atau } \\
\text { petugas medis } \\
\text { 4. Persepsi atau pengetahuan } \\
\text { tentang kelengkapan rekam } \\
\text { medis antara petugas } \\
\text { rekam medis dan perawat } \\
\text { berbeda } \\
\text { 5. kurangnya kesadaran dan } \\
\text { waktu untuk mengisi rekam } \\
\text { medis secara lengkap }\end{array}$ \\
\hline $\begin{array}{l}\text { Machine / } \\
\text { Kebujakan }\end{array}$ & $\begin{array}{ll}\text { 1. } & \text { Belum diterapkan dengan } \\
\text { maksimal komunikasi } \\
\text { seperti tidak terdapat } \\
\text { wadah komunikasi serta } \\
\text { tidak ada rapat membahas } \\
\text { kelengkapan rekam medis } \\
\text { 2. } \quad \begin{array}{l}\text { Tidak ada evaluasi dari } \\
\text { kelengkapan rekam medis }\end{array} \\
\text { 3. } \quad \begin{array}{l}\text { Belum adanya monitoring } \\
\text { dan evaluasi mengenai }\end{array} \\
\text { rekam medis } \\
\text { Tidak adanya sanksi untuk } \\
\text { tenaga kesehatan yang } \\
\text { tidak mengisi lengkap } \\
\text { rekam medis }\end{array}$ \\
\hline $\begin{array}{l}\text { Method / } \\
\text { Prosedur } \\
\text { kerja }\end{array}$ & $\begin{array}{ll}\text { 1. } & \text { Tidak ada sosialisasi SPO } \\
\text { pengisian rekam medis } \\
\text { 2. } \\
\text { Tidak ada panduan dan } \\
\text { SPO pengisian rekam } \\
\text { medis } \\
\text { 3. }\end{array}$ \\
\hline $\begin{array}{l}\text { Material / } \\
\text { Alat dan }\end{array}$ & $\begin{array}{l}\text { 1. Susunan rekam medis } \\
\text { kurang sistematis }\end{array}$ \\
\hline
\end{tabular}




\begin{tabular}{lll}
\hline bahan & 2. & $\begin{array}{l}\text { Tidak ada data tentang } \\
\text { ketidaklengkapan } \\
\text { pengisian rekam medis } \\
\text { Belum ada ruang khusus } \\
\text { untuk melengkapi rekam } \\
\text { medis } \\
\text { Formulir rekam medis } \\
\text { perlu } \\
\text { disederhanakan }\end{array}$ \\
& 5. & $\begin{array}{l}\text { Formulir analisis kuantitatif } \\
\text { belum mencakup } \\
\text { komponen dasar analisis } \\
\text { kuantitatif }\end{array}$ \\
\hline Money/ & 1. & $\begin{array}{l}\text { Sumber dana terbatas } \\
\text { untuk mendukung } \\
\text { kelengkapan rekam medis } \\
\text { Pendanaan }\end{array}$ \\
& 2. & $\begin{array}{l}\text { Sumber dana untuk } \\
\text { mendukung kelengkapan } \\
\text { rekam medis sudah ada } \\
\text { tetapi belum cukup }\end{array}$ \\
\hline
\end{tabular}

Sumber : Data hasil analisis

Berdasarkan literatur review didapatkan 5 artikel yang sesuai dengan judul. Faktor penyebab ketidaklengkapan pengisian rekam medis dapat dilihat dari faktor $5 \mathrm{M}$ meliputi (Man, Machine, Method, Material, Money). Dari 5 artikel tersebut, penelitian mengambil 9 hingga 27 responden yang terdiri dari para pemberi asuhan dengan metode deskriptif dan kuantitatif. Tujuan penelitian untuk mengetahui faktor penyebab ketidaklengkapan pengisian rekam medis. Metode pengambilan data dalam artikel yang dikumpulkan yaitu 1 artikel menggunakan kuesioner, dan 4 diantaranya menggunakan pedoman wawancara. Teknik pengambilan sampel dari ke 5 artikel tersebut 4 diantaranya dilakukan secara random, 1 dilakukan secara purposive sampling. Tempat penelitian dari ke 5 artikel tersebut dilakukan di 4 rumah sakit dan 1 dilakukan di puskesmas.

Faktor penyebab ketidaklengkapan pengisian rekam medis dapat dilihat dari faktor 5 M (Man, Machine, Method, Material, Money). Dari 5 artikel yang di literatur review untuk menunjang literatur yang peneliti lakukan dapat dijabarkan sebagai berikut :

\section{A. Faktor penyebab ketidaklengkapan pengisian rekam medis dilihat dari faktor Man}

Berdasarkan artikel yang di peroleh dilihat dari faktor Man penyebab ketidaklengkapan pengisian rekam medis dapat dilihat dari segi pengetahuan dan motivasi hal ini didukung oleh jurnal yang ditemukan yaitu menurut (Cicilia et al., 2015) dan (Fantri, et al., 2015)

1. Pengetahuan

Dilihat dari pengetahuan, masih ada petugas kesehatan yang belum mengetahui bahwa rekam medis harus segera dilengkapi 24 jam saat pasien telah dinyatakan pulang. Pengetahuan akan kelengkapan rekam medis sangat penting bagi petugas kesehatan baik itu dokter, perawat terutama petugas rekam medis. Pengetahuan yang tinggi terhadap kegunaan dan manfaat dari rekam medis akan membuat petugas lebih memperhatikan kelengkapan rekam medis.

2. Motivasi

Dilihat dari segi motivasi ternyata masih banyak petugas yang memiliki motivasi yang rendah dalam pengisian dokumen rekam medis

3. Penyebab lain dari ketidaklengkapan pengisian rekam medis yaitu kurangnya kesadaran dan waktu dari para pemberi asuhan untuk mengisi rekam medis secara lengkap. Hal ini didukung oleh jurnal yang ditemukan yaitu menurut (Nurhadiah et al., 2016) (Karmila, 2019) dan (Siti et al., 2017)

\section{B. Faktor penyebab ketidaklengkapan pengisian rekam medis dilihat dari faktor Machine}

Faktor penyebab ketidaklengkapan pengisian rekam medis dilihat dari dari faktor Machine atau kebijakan. Machine adalah rangkaian atau konsep dan asas yang menjadi pedomaman dan dasar rencana dalam pelaksanaan suatu pekerjaan (Simamora, 2012). Berdasarkan arikel yang di peroleh dilihat dari unsur Machine. Penyebab ketidaklengkapan pengisian rekam medis dapat dilihat dari faktor Machine meliputi komunikasi dan pengendalian.

1. Komunikasi

Dilihat dari komunikasi tidak terdapatnya wadah komunikasi seperti rapat yang membahas 
kelengkapan rekam medis serta rapat tersebut tidak melibatkan para pemberi asuhan seperti dokter, perawat dan petugas medis lainnya.

2. Pengendalian

Dilihat dari Pengendalian belum terdapat bentuk evaluasi dan monitoring mengenai kelengkapan rekam medis. Hal ini didukung oleh jurnal yang di temukan yaitu menurut (Cicilia et al., 2015) (Nurhadiah et al., 2016) (Karmila, 2019) dan (Fantri et al., 2015). Evaluasi meliputi kegiatan yang dilaksanakan agar dapat mencapai tujuan yang direncanakan. Monitoring meliputi pemantuan pekerjaan yang masih berjalan. Evaluasi dan monitoring ini berupa kelengkapan pengisian rekam medis agar pengisian rekam medis lengkap dengan standar $100 \%$ (Kepmenkes, No. 129 Tahun 2008)

3. Menurut penelitian (Siti et al., 2017) ketidaklengkapan rekam medis dari unsur Machine dapat disebabkan tidak adanya sanksi untuk para pemberi asuhan yang tidak mengisi secara lengkap rekam medis.

\section{Faktor penyebab ketidaklengkapan pengisian rekam medis dilihat dari faktor Method}

Faktor penyebab ketidaklengkapan pengisian rekam medis dilihat dari faktor Method atau prosedur kerja. Method merupakan tata cara kerja sebagai acuan untuk melaksanakan kegiatan (Simamora, 2012). Berdasarkan arikel yang di peroleh dilihat dari faktor Method. Penyebab ketidaklengkapan pengisian rekam medis dari faktor Method atau prosedur kerja penyebabnya adalah sosialisasi SPO (standar prosedur operasional) rekam medis yang belum optimal sehingga para pemeberi asuhan tidak mengisi rekam medis sesuai SPO. Hal ini didukung oleh jurnal yaitu menurut (Cicilia et al., 2015) (Karmila, 2019) dan (Siti et al., 2017). Bentuk sosialisasi SPO berupa cara pengisian rekam medis sesuai SPO seperti pengisian identitas pasien nama, jenis kelamin dan pengisian No. RM. Sedangkan menurut (Nurhadiah et al., 2016) adanya rumah sakit yang belum memiliki SPO pengisian rekam. Hal ini mengakibatkan tidak adanya acuan bagi petugas terkait dalam melakukan pengisian rekam medis sehingga menimbulkan perbedaan persepsi tentang kelengkapan rekam medis. Penyebab lain adalah pedoman tentang kelengkapan rekam medis perlu dikaji ulang (Fantri et al., 2015)

\section{Faktor penyebab ketidaklengkapan pengisian rekam medis dilihat dari faktor Material}

Faktor penyebab ketidaklengkapan pengisian rekam medis dilihat dari faktor Material atau alat dan bahan. Alat dan bahan harus dapat digunakan sebagai salah satu sarana (Simamora, 2012). Berdasarkan arikel yang di peroleh dilihat dari faktor Material. Penyebab ketidaklengkapan pengisian rekam medis dari faktor Material lebih berkaitan dengan susunan formulir yang tidak sistematis dimana para pemberi asuhan yang biasanya tergesa-gesa akan merasa kesulitan dalam mengisi formulir rekam medis pasien karena susunannya yang kurang sistematis. Hal ini didukung oleh jurnal menurut (Cicilia et al., 2015) (Nurhadiah et al., 2016) (Karmila, 2019). Penyebab lain adalah dokumen rekam medis perlu disederhanakan (Fantri et al., 2015). Sedangkan menurut (Siti et al., 2017) Formulir analisis kuantitatif yang digunakan masih belum mencakup komponen dasar analisis kuantitatif.

\section{E. Faktor penyebab ketidaklengkapan pengisian rekam medis dilihat dari faktor Money}

Faktor penyebab ketidaklengkapan pengisian rekam medis dilihat dari faktor Money atau pendanaan. Money berhubungan dengan besarnya anggaran yang harus disediakan untuk menunjang suatu kegiatan (Simamora, 2012). Berdasarkan arikel yang di peroleh dilihat dari unsur Money penyebab ketidaklengkapan rekam medis adalah sumber dana yang terbatas untuk mendukung kelengkapan rekam medis hal 
ini di dukung oleh penelitian (Cicilia dkk., 2015) (Nurhadiah et al., 2016) (Fantri et al., 2015) dan (Siti et al., 2017). Dana sangat diperlukan untuk menjamin ketersediaan dokumen rekam medis bagi pasien. Dana yang memadai akan menunjang kegiatan pelayanan rekam medis menjadi lebih baik

\section{Simpulan}

Berdasarkan hasil litetatur review adapun hasil informasi yang diperoleh antara lain

1. ketidaklengkapan pengisian rekam medis dilihat dari faktor man atau manusia yaitu kurangnya pengetahuan, motivasi serta kesadaran dari para pemberi asuhan untuk mengisi rekam medis.

2. ketidaklengkapan pengisian rekam medis dilihat dari faktor machine atau kebijakan yaitu belum terlaksananya rapat sebagai wadah komunikasi antara pemberi asuhan dan manajemen yang membahas evaluasi dan monitoring serta sanksi bagi petugas yang tidak mengisi rekam medis dengan lengkap.

3. ketidaklengkapan pengisian rekam medis dilihat dari faktor method atau prosedur kerja yaitu kurangnya sosialisasi pengisian rekam medis dan belum terdapat SPO pengisian rekam medis.

4. ketidaklengkapan pengisian rekam medis dilihat dari faktor material atau alat dan bahan lebih berkaitan dengan dokumen rekam medis seperti susunan formulir rekam medis yang kurang sistematis serta desain rekam medis perlu disederhanakan.

5. ketidaklengkapan pengisian rekam medis dilihat dari faktor money atau pendanaan yaitu terbatasnya ketersediaan dana atau anggaran untuk mendukung kegiatan pelayanan rekam medis.

\section{Saran}

Berdasarkan hasil literatur review adapun solusi yang dapat digunakan untuk menghindari ketidaklengkapan pengisian rekam medis rawat inap, maka penulis memberikan saran antara lain:

1. Rumah sakit dari faktor Man atau manusia sebaiknya meningkatkan pengetahuan, motivasi dan kesadaran dari para pemberi asuhan tentang rekam medis

2. Rumah sakit dari faktor Machine atau kebijakan sebaiknya terdapat wadah komunikasi seperti rapat yang membahas kelengkapan rekam medis serta melibatkan para pemberi asuhan.

3. Dalam hal pengendalian sebaiknya ada laporan dan evaluasi mengenai rekam medis, serta perlu adanya sanksi bagi petugas yang tidak lengkap mengisi rekam medis

4. Rumah sakit dari faktor Method atau prosedur kerja sebaiknya mensosialisasikan standar prosedur operasional (SPO) kelengkapan rekam medis untuk mempermudah para pemberi asuhan dalam pengisian rekam medis.

5. Rumah sakit dari faktor Material atau alat dan bahan sebaiknya mengkaji ulang susunan dan desain dari formulir rekam medis sesuai dengan inovasi terkini

6. Rumah sakit dari faktor Money atau pendanaan sebaiknya menyediakan anggaran untuk mendukung kegiatan pelayanan rekam medis.

\section{Ucapan terimakasih}

Terimakasih disampaikan kepada Poltekkes Kemenkes semarang yang telah mendanai keberlangsungan jurnal ini. Serta kepada dosen pembimbing yang telah membantu pelaksanaan jurnal ini.

\section{Daftar Pustaka}

Budi, S. C. (2011). Manajemen Unit Kerja Rekam Medis . Yogyakarta: Quantum Sinergi Media.

Cicilia Lihawa, M. M. (2015). Faktor-Faktor Penyebab Ketidaklengkapan Pengisian 
Rekam Medis Dokter di Ruang Rawat Inap RSI Unisma Malang. Retrieved November 28, 2019, from Jurnal Kedokteran Brawijaya, Vol. 28 , No. 2 Tahun. 2015 https://jkb.ub.ac.id/index.php/jkb/a rticle/view/957/477 DepKes RI Dirjen YanMed. (2006). Pedoman Pengelolaan Rekam Medis Rumah Sakit di Indonesia. Jakarta

Devhy, N., Widana, A. (2019). Analisis Kelengkapan Rekam Medis Rawat Inap Rumah Sakit Ganesha Di Kota Gianyar. Retrieved Desember 2, 2019, from Jurnal Rekam Medis dan Informasi Kesehatan, Vol. 2, No. 2, Tahun. 2019 http://dx.doi.org/10.31983/jrmik.v2i 2.5353

Direktorat Jenderal Pelayanan Medik. (2006). Pedoman Pengelolaan Rekam Rumah Sakit di Indonesia Rev.II.. Jakarta : DepKes RI

Fantri Pamungkas, T. H. (2015). Identifikasi Ketidaklengkapan Dokumen Rekam Medis Rawat Inap di RSUD Ngudi Waluyo Wlingi. Retrieved januari 2, 2020, from Jurnal Kedokteran Brawijaya, Vol. 28 , No. 2, Tahun. 2015 https://jkb.ub.ac.id/index.php/jkb/a rticle/download/1049/456

Hatta, G. (2013). Pedoman Manajemen Informasi Kesehatatan di Sarana Pelayanan Kesehatan. Jakarta: UI-Press.

Karmila. (2019). Faktor-Faktor Penyebab Ketidaklengkapan Pengisian Dokumen Rekam Medis Pasien Rawat Jalan Berdasarkan Fishbonediagram
Dipuskesmas Jetis Ponorogo. Retrieved januari 3, 2020, from Jurnal Prodi D III Rekam Medis dan Informasi Kesehatan, Vol. 4, No. 1, Tahun. 2019 https://stikesponorogo.ac.id/ojs/ind ex.php/cakrabuanakesehatan/article /download/110/63/

Keputusan Menteri Kesehatan No. 129 Tahun 2008 Standar Tentang Sandar Pelayanan Minimal Rumah Sakit

Nurhadiah, T. H. (2016). Faktor-Faktor Penyebab Ketidaklengkapan Pengisian Rekam Medis di Rumah Sakit Universitas Muhammadyah Malang. Retrieved Desember 1, 2019, from Jurnal Kedokteran Brawijaya, Vol. 5, No. 1, Tahun. 2016 http://jkb.ub.ac.id/index.php/jkb/ar ticel/view/1642

Peraturan Menteri Kesehatan Republik Indonesia

No.269/Menkes/Per/III/2008

Tentang Rekam Medis. Jakarta: Departemen Kesehatan Republik Indonesia

Simamora, R. H. (2012). Manajemen. Jakarta: EGC.

Siti Nadya Ulfa, L. W. (2017). Faktor-Faktor Yang Mempengaruhi Kelengkapan Rekam Medis Rawat Inap dengan Menggunakan Diagram Fishbone di Rumah Sakit Pertamina Jaya Tahun 2017. Retrieved November 30, 2019, from Jurnal INOHIM, Vol. 5, No. 1, Tahun.

2017 https://ejurnal.esaunggul.ac.id/inde x.php/Inohim/article/view/2105 